\title{
Erratum: Zahn et al. Manipulation of Medicinal Products for Oral Administration to Paediatric Patients at a German University Hospital: An Observational Study. Pharmaceutics 2020, 12, 583
}

\author{
Julia Zahn*(D), André Hoerning (D), Regina Trollmann (D), Wolfgang Rascher and Antje Neubert *(D)

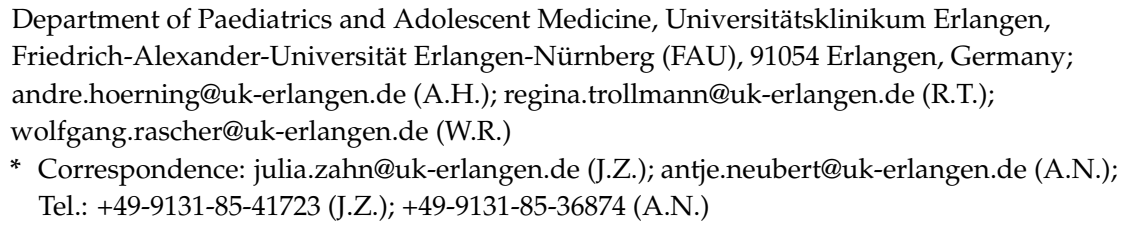

Department of Paediatrics and Adolescent Medicine, Universitätsklinikum Erlangen, Friedrich-Alexander-Universität Erlangen-Nürnberg (FAU), 91054 Erlangen, Germany; andre.hoerning@uk-erlangen.de (A.H.); regina.trollmann@uk-erlangen.de (R.T.); wolfgang.rascher@uk-erlangen.de (W.R.)

* Correspondence: julia.zahn@uk-erlangen.de (J.Z.); antje.neubert@uk-erlangen.de (A.N.); Tel.: +49-9131-85-41723 (J.Z.); +49-9131-85-36874 (A.N.)

check for

updates

Citation: Zahn, J.; Hoerning, A.;

Trollmann, R.; Rascher, W.; Neubert,

A. Erratum: Zahn et al. Manipulation of Medicinal Products for Oral Administration to Paediatric Patients at a German University Hospital: An Observational Study. Pharmaceutics 2020, 12, 583. Pharmaceutics 2021, 13, 939. https://doi.org/10.3390/ pharmaceutics13070939

Received: 29 April 2021

Accepted: 18 June 2021

Published: 24 June 2021

Publisher's Note: MDPI stays neutral with regard to jurisdictional claims in published maps and institutional affiliations.

Copyright: (c) 2021 by the authors. Licensee MDPI, Basel, Switzerland. This article is an open access article distributed under the terms and conditions of the Creative Commons Attribution (CC BY) license (https:/ / creativecommons.org/licenses/by/ $4.0 /)$.
The authors wish to make the following corrections to the affiliation and acknowledgments part [1]. The affiliation of all of the authors of "Department of Paediatrics and Adolescent Medicine, Universitätsklinikum Erlangen, 91054 Erlangen, Germany", should be "Department of Paediatrics and Adolescent Medicine, Universitätsklinikum Erlangen, Friedrich-Alexander-Universität Erlangen-Nürnberg (FAU), 91054 Erlangen, Germany". The updated "Acknowledgments" section is as follows "The authors would like to thank the nursing staff for a valuable exchange on the subject of manipulation and the opportunity to observe dispensing of medicines in clinical practice. The present work was performed in (partial) fulfilment of the requirements for obtaining the degree Dr. rer. biol. hum.".

The authors would like to apologize for any inconvenience caused to the readers by these changes.

\section{Reference}

1. Zahn, J.; Hoerning, A.; Trollmann, R.; Rascher, W.; Neubert, A. Manipulation of Medicinal Products for Oral Administration to Paediatric Patients at a German University Hospital: An Observational Study. Pharmaceutics 2020, 12, 583. [CrossRef] 